\title{
PENGARUH KREDIBILITAS BRAND AMBASSADOR SELEBRITI TERHADAP KEPUTUSAN PEMBELIAN PRODUK PADA IKLAN WARDAH VERSI DEWI SANDRA (STUDI KASUS MAHASISWI UIN JAKARTA FAKULTAS EKONOMI DAN BISNIS) \\ Nisa Sabrina ${ }^{1}$, Azwar ${ }^{2)}$ dan Nidia Sofa ${ }^{3)}$ \\ Jurusan Administrasi Niaga, Program Studi Administrasi Bisnis Terapan \\ Politeknik Negeri Jakarta \\ Email:.1nisasabrina2@yahoo.com, ${ }^{2}$ azwar.pnj@gmail.com, ${ }^{3}$ nidia_sofa@yahoo.com
}

\begin{abstract}
The Influence of Celebrity Brand Ambassador Credibility against Wardah's Purchase Decision. Wardah ad version of Dewi Sandra. Economics and Business Faculty. State Islamic University of Syarif Hidayatullah Jakarta 2017. This study aims to determine and analyze the influence of the credibility of Dewi Sandra as a celebrity brand ambassador against consumer purchasing decisions on Wardah cosmetic products. The research method used is quantitative research method. The results of the analysis are presented in the form of numbers then explained and interpreted in a description. There are 100 samples used in this study, which is a student of Faculty of Economics and Business. State Islamic University Syarif Hidayatullah Jakarta who had bought and used Wardah beauty products. In this research used 2 variables namely credibility brand ambassador as independent variable and purchase decision as dependent variable. Data analysis in this research use validity test, reliability test, normality test, linearity test and hypothesis test consisting of simple linear regression test, simple correlation test, coefficient of determination test (R2), and T significance test. Data processing in this research is assisted By SPSS version 24.00 for windows. The results of this study indicate on the simple correlation test (R2) that brand ambassador credibility has an influence of $25.9 \%$ on purchasing decisions, while the remaining $74.1 \%$ of consumer purchasing decision making process influenced by other variables not examined in this study.
\end{abstract}

Keywords: brand ambassador credibility, purchase decision, Wardah

\section{Abstrak}

Pengaruh Kredibilitas Brand ambassador Selebriti terhadap Keputusan Pembelian produk Wardah. Iklan Wardah versi Dewi Sandra. Fakultas Ekonomi dan Bisnis. Universitas Islam Negeri Syaarif Hidayatullah Jakarta 2017. Penelitian ini bertujuan untuk mengetahui dan menganalisa pengaruh kredibilitas Dewi Sandra sebagai brand ambassador selebriti terhadap keputusan pembelian konsumen pada produk kosmetik Wardah. Metode penelitian yang digunakan adalah metode penelitian kuantitatif. Hasil analisis disajikan dalam bentuk angka-angka kemudian dijelaskan dan diinterpretasikan dalam suatu uraian. Terdapat 100 sampel yang digunakan dalam penelitian ini, yang merupakan mahasiswi Fakultas Ekonomi dan Bisnis. Universitas Islam Negeri Syaarif Hidayatullah Jakarta yang pernah membeli dan menggunakan produk kecantikan Wardah. Dalam penelitian ini digunakan 2 variabel yaitu kredibilitas brand ambassador sebagai variabel bebas dan keputusan pembelian sebagai variabel terikat. Analisis data pada penelitian ini menggunakan uji validitas, uji reliabilitas, uji normalitas, uji linearitas dan uji hipotesis yang terdiri dari uji regresi linear sederhana, uji korelasi sederhana, uji koefisien determinasi (R2), dan uji signifikansi $T$. Pengolahan data pada penelitian ini dibantu oleh program SPSS versi 24.00 for windows. Hasil penelitian ini menunjukkan pada uji korelasi sederhana (R2) bahwa kredibilitas brand ambassador 
memiliki pengaruh sebesar 25,9\% terhadap keputusan pembelian, sedangkan sisanya yaitu 74,1\% proses pengambilan keputusan pembelian konsumen dipengaruhi oleh variabel-variabel lainnya yang tidak diteliti dalam penelitian ini.

Kata Kunci: Kredibilitas Brand Ambassador, Keputusan Pembelian, Wardah

\section{PENDAHULUAN}

\section{Latar Belakang}

Dalam menjalankan sebuah usaha, setiap wirausahan menginginkan produk atau jasa yang ia tawarkan dikenal oleh konsumen. Begitu pula dengan penulis yang kebetulan memiliki usaha dalam bidang jasa makeup artist. Diperlukan cara yang tepat dan kreatif untuk meningkatkan penjualan.

Berhasilnya sebuah bisnis dapat dilihat berdasarkan tingginya penjualan. Semakin banyak orang yang dijangkau, semakin banyak pula angka penjualan yang bisa dicapai. Banyak usaha yang beredar di pasaran namun tidak semua produk tersebut dapat mencapai kesuksesan seperti yang diharapkan. Oleh karena itu, pemasaran merupakan hal yang harus benar-benar diperhatikan untuk seorang entrepreneur. Strategi yang ampuh dan efektif dalam meningkatkan penjualan produk atau jasa dapat menggunakan berbagai cara, sistem dan inovasi. Salah satunya dengan cara penggunaan brand ambassador dalam memasarkan produknya, sama halnya dengan penulis yang sedang mencoba melakukan hal yang serupa.

Brand ambassador biasanya adalah orang-orang yang telah banyak dikenal publik, misalnya seperti aktor, atlet, penyanyi dan lain sebagainya. Penggunaan brand ambassador merupakan strategi kreatif yang dilakukan perusahaan untuk meningkatkan minat beli masyarakat. Brand ambassador diharapkan menjadi juru bicara merek agar cepat melekat di benak konsumen, sehingga konsumen mau membeli produk yang diiklankan.

Saat ini, banyak strategi iklan yang dilakukan pengiklan untuk memasarkan produknya, yakni salah satunya dengan menggunakan selebriti sebagai model iklannya. Iklan merupakan bagian dari bauran pemasaran (marketing mix). Sederahananya, iklan dapat didefinisikan sebagai pesan yang menawarkan suatu produk yang ditujukan kepada masyarakat melalui suatu media. Salah satu alat promosi yang digunakan untuk pengantar pesan yang bertujuan untuk membentuk dan merubah perilaku konsumen ialah iklan, sedangkan media yang digunakan untuk menyampaikan pesan dalam bentuk iklan ini diantaranya adalah televise, majalah, surat kabar dan radio. Agar iklan dapat mencapai kesuksesan yakni dapat mencapai target konsumen maka iklan dibuat semenarik mungkin sehingga konsumen akan dengn mudah mengingat dan mempercayainya

Perusahaan harus memilih brand ambassador yang tepat dan dianggap mewakili citra produk perusahaan, akan tetapi pemilihan model yang tepat tidaklah mudah, tentunya banyak sekali hal-hal yang menjadi bahan pertimbangan, yang menjadi salah satu pertimbangannya adalah kredibilitas perusahaan itu sendiri dan kredibilitas brand ambassador yang dapat mewakili brand dan citra perusahaan tersebut. Model yang dipilih haruslah seseorang yang mewakili karakteristik produk dan juga harus mampu menjadi duta produk selaras dengan citra produk yang ingin dikembangkan.

Saat ini di Indonesia telah banyak perusahaan yang menggunakan jasa selebriti sebagai brand ambassador dalam mengiklankan produk, salah satunya ialah Wardah. Kemunculan kosmetik dengan brand luar tidak mengurangi produsen kosmetik dalam negeri untuk memasarkan produknya juga. Dapat terlihat masih tingginya minat konsumen pada kosmetik dalam negeri yang diminati oleh kalangan menengah yang menjadi pemicu pesatnya 
penjualan kosmetik dalam negeri dan salah satu produk yang sedang menggarap pasar sekarang ialah Wardah. Wardah dengan banyak seri atau jenis kosmetik yang dikeluarkan mampu memberikan banyak pilihan bagi konsumen dengan mencocokan kebutuhan dengan produk yang tersedia. Selain itu, harga yang terjangkau namun mampu memberikan manfaat-manfaat lebih ini yang menjadikan Wardah sebagai salah satu produk kosmetik dalam negeri yang penjualan dan ketenarannnya menyamai produk kosmetik luar.

Berdasarkan data yang dilansir pada http://www.topbrand-award.com/ tercatat Wardah menempati urutan pertama dalam beberapa penjualan jenis produk tahun 2016. Selain itu, pada tahun 2013, Wardah menetapkan Dewi Sandra sebagai brand ambassador Wardah.

Untuk meningkatkan penjualan dan menguasai pangsa pasar di Indonesia, Wardah menetapkan strategi pemasaran dengan menggunakan Dewi Sandra sebagai brand ambassador Wardah. Penggunaan Dewi Sandra sebagai brand ambassador selebriti dirasa sudah tepat karena jika dilihat dari prestasi yang telah dicapai oleh Dewi Sandra, Dewi merupakan artis yang berprestasi dalam bidangnya. Begitu pula dengan produk Wardah yang sudah menjadi top brand selama beberapa tahun belakangan ini. Kolaborasi antara Dewi Sandra dan Wardah diharapkan mampu menarik perhatian konsumen di Indonesia pada produk Wardah sehingga memunculkan minat untuk membeli produk kosmetik Wardah.

Berdasarkan latar belakang yang telah diketahui jika menggunakan brand ambassador yang memiliki kredibilitas baik maka akan berdampak pada penngkatan penjualannya, begitu pun sebaliknya, jika memilih brand ambassador yang kurang baik maka akan berdampak pada penurunan penjualannya. Maka dari itu peneliti tertarik untuk meneliti mengenai "Pengaruh Kredibilitas
Brand Ambassador Selebriti terhadap Keputusan Pembelian produk Wardah pada iklan Wardah versi Dewi Sandra (Studi Kasus pada Mahasiswi Fakultas Ekonomi dan Bisnis UIN Syarif Hidayatullah Jakarta)”

\section{Tujuan}

Adapun tujuan yang akan diteliti adalah untuk mengetahui dan menganalisa pengaruh kredibilitas Dewi Sandra sebagai brand ambassador selebriti terhadap keputusan pembelian konsumen pada produk kosmetik Wardah.

\section{Permasalahan}

Penulis tertarik untuk mengkaji lebih lanjut dampak dari penggunaan brand ambassador selebriti terhadap keputusan pembelian konsumen yang dilakukan oleh pihak Wardah, sehingga permasalahan yang akan dibahas dalam penelitian ini, yaitu: Bagaimana kredibilitas Dewi Sandra sebagai brand ambassador selebriti mampu mempengaruhi keputusan pembelian konsumen pada produk kosmetik Wardah?.

\section{Kajian Pustaka}

Penelitian ini didasarkan pada beberapa teori sebagai berikut:

\section{Pengertian Komunikasi}

Menurut Belch dan Belch (2009:128) Komunikasi didefinisikan sebagai berlalunya informasi, pertukaran ide atau proses pembentukan keawaman atau kesatuan pemikiran antara pengirim dan penerima.

\section{Komunikasi Pemasaran}

Menurut Terence A shimp (2003:4), komunikasi pemasaran merupakan gabungan semua unsur dalam bauran pemasaran merek, yang memfasilitasi terjadinya pertukaran dengan menciptakan suatu arti yang disebarluaskan kepada pelanggan atau kliennya. 


\section{Iklan}

Penjelasan bauran pemasaran Menurut Kamus Besar Bahasa Indonesia iklan merupakan berita pesanan untuk mendorong, membujuk khalayak ramai agar tertarik pada barang dan jasa yang ditawarkan. Adapun fungsi periklanan menurut Terence A. Shimp (2003:357) sebagai berikut:

a. Memberikan informasi

b. Membujuk dan mempengaruhi

c. Mengingatkan

d. Memberikan nilai tambah

e. Mendampingi

\section{Brand Ambassador}

Menurut Terence A. Shimp (2003:329) brand ambassador ialah pendukung iklan atau yang dikenal juga sebagai bintang iklan dalam mendukung iklan pro dukungan, sedangkan proses pemilihannya berdasarkan kepentingan nya yang memiliki beberapa pertimbangan.

\section{Karakteristik Brand Ambassador}

Berdasarkan penelitian yang dilakukan oleh Ohanian (1990) dalam Royan (2004:132), terdapat tiga dimensi skala pengukuran kredibilitas brand ambassador yaitu:

Expertise: Keahlian yang mengacu pada pengetahuan, pengalaman atau keterampilan yang dimiliki seseorang pendukung yang berhubungan dengan topic yang diwakilinya.

Trustworthiness: Paradigma kepercayaan atau trust dalam proses komunikasi merupakan tingkat keyakinan dan tingkat penerimaan dari penerima pesan terhadap brand ambassador serta pesan yang disampaikan oleh selebriti tersebut

Attractiveness: Selebriti yang memiliki daya tarik yang konsisten lebih disukai dan memiliki dampak yang positif terhadap produk yang diasosiasikan dengan mereka.

\section{Kredibilitas}

Menurut Rakhmat Jalaludin (2005:257) menyatakan bahwa, Kredibilitas adalah persepsi yang dimiliki oleh khalayak tentang komunikator. Dampak pesan terhadap khalayak dipengaruhi oleh bagaimana khalayak memandang pengirim pesan atau bagaimana kredibilitas komunikator dalam pandangan khalayak.

\section{Keputusan Pembelian}

Menurut Kotler (2004:204) proses keputusan pembelian konsumen dijelaskan sebagai berikut:

Pengenalan kebutuhan, adalah tahap pertama proses keputusan pembelian, yaitu konsumen menyadari suatu masalah atau kebutuhan.

Pencarian informasi, adalah tahap proses kebutuhan pembeli dengan cara mencari informasi lebih banyak. Konsumen mungkin hanya memperbesar perhatian atau melakukan pencarian informasi secara aktif.

Evaluasi alternatif, adalah tahap proses keputusan membeli konsumen dengan menggunakan informasi untuk mengevaluasi merek alternatif dalam sekelompok pilihan.

Keputusan pembelian, yaitu keputusan konsumen untuk membeli atau tidak membeli suatu produk atau jasa merupakan alternatif pilihan yang penting bagi pemasar.

Perilaku pasca pembelian, adalah tahap proses keputusan pembeli, yaitu konsumen mengambil tindakan selanjutnya setelah pembelian, berdasarkan kepuasan atau ketidakpuasan konsumen.

\section{METODOLOGI PENELITIAN}

Metode penelitian yang digunakan dalam penelitian ini yaitu penelitian survei yang merupakan salah satu bagian dari pendekatan penelitian kuantitatif. Penelitian ini termasuk penelitian kuantitatif karena teknik analisis data yang digunakan adalah teknik analisis statistik dengan menggunakan regresi linier sederhana.

Populasi pada penelitian ini adalah mahasiswi Fakultas Ekonomi dan Bisnis 
Universitas Islam Negeri Syarif Hidayatullah Jakarta. Pemilihan teknik sampling dalam penelitian ini adalah nonprobability sampling dengan metode pengambilan sampel purposive sampling. Dalam menentukan ukuran sampel penelitian ini ditentukan dengan teknik sampling kuota yang berjumlah 100 orang responden. Teknik pengumpulan data dilakukan dengan melakukan observasi ke lapangan dan menyebarkan instrument penelitian berupa kuesioner ke responden, Tipe skala yang digunakan untuk mengukur kedua variabel pada penelitian ini adalah skala interval. Data-data yang diperoleh dari pengukuran dengan instrument sikap dengan skala likert misalnya adalah berbentuk data interval. Penggunaan skala interval dalam penelitian ini dikarenakan peneliti ingin mengetahui seberapa kuat responden setuju atau tidak setuju dengan pernyataan yang ada dalam kuesioner melalui skala likert atau skala 4 titik.

Teknik pengolahan data melalui tahapan berikut:

Editing adalah proses yang dilakukan setelah semua data terkumpul untuk melihat apakah jawaban-jawab kuesioner telah terisi atau belum.

Coding adalah proses pemberian kode tertentu terhadap aneka ragam kuesioner yang sama. Pada penelitian ini peneliti membuat kode dalam kuesioner.

Tabulasi adalah proses pengelompokkan data atas semua jawabanjawaban dengan teliti dan teratur, kemudian dihitung dan dijumlahkan sampai terwujud dalam bentuk tabel yang berguna dan berdasrkan tabel untuk mendapatkan hubungan-hubungan antara variabel-variabel yang ada.

Scoring adalah proses yang berupa pemberian Skor pada jawaban kuesioner, dalam penelitian ini menggunkan skala 4 tingkat (Likert).

Untuk uji instrumen penelitian menggunakan uji validitas dan realibilitas. Untuk uji hipotesis asosiatif/hubungan yang datanya berbentuk interval menggunakan teknik analis regresi linear sederhana, analisis korelasi sederhana, uji determinasi dan uji parsial (uji T).

\section{HASIL DAN PEMBAHASAN}

Bab hasil penelitian dan pembahasan ini berisi penjelasan mengenai data dan pembahasan temuan penelitian.

\section{Uji Validitas Instrumen}

Berdasarkan hasil pre-test yang dilakukan, maka hasil uji validitas variabel kredibilitas brand ambassador dapat dilihat sebagai berikut:

Tabel 1. Hasil Uji Validitas Variabel X

\begin{tabular}{|c|c|c|c|}
\hline Pertanyaan & r hitung & $\mathrm{r}$ tabel & Keterangan \\
\hline 1 & 0,730 & 0,3783 & Valid \\
\hline 2 & 0,497 & 0,3783 & Valid \\
\hline 3 & 0,747 & 0,3783 & Valid \\
\hline 4 & 0,658 & 0,3783 & Valid \\
\hline 5 & 0,182 & 0,3783 & Tidak Valid \\
\hline 6 & 0,660 & 0,3783 & Valid \\
\hline 7 & 0,783 & 0,3783 & Valid \\
\hline 8 & 0,588 & 0,3783 & Valid \\
\hline 9 & 0,581 & 0,3783 & Valid \\
\hline 10 & 0,720 & 0,3783 & Valid \\
\hline 11 & 0,720 & 0,3783 & Valid \\
\hline 12 & 0,077 & 0,3783 & Tidak Valid \\
\hline 13 & 0,606 & 0,3783 & Valid \\
\hline 14 & 0,579 & 0,3783 & Valid \\
\hline 15 & 0,405 & 0,3783 & Valid \\
\hline 16 & 0,730 & 0,3783 & Valid \\
\hline 17 & 0,574 & 0,3783 & Valid \\
\hline 18 & 0,422 & 0,3783 & Valid \\
\hline 19 & 0,749 & 0,3783 & Valid \\
\hline 20 & 0,124 & 0,3783 & Tidak Valid \\
\hline 21 & 0,258 & 0,3783 & Tidak Valid \\
\hline 22 & 0,418 & 0,3783 & Valid \\
\hline 23 & 0,697 & 0,3783 & Valid \\
\hline 24 & 0,418 & 0,3783 & Valid \\
\hline 25 & 0,764 & 0.3783 & Valid \\
\hline
\end{tabular}

Dan hasil uji validitas variabel proses keputusan pembelian dapat dilihat sebagai berikut: 
Tabel 2. Hasil Uji Validitas Variabel Y

\begin{tabular}{llll}
\hline Pertanyaan & r hitung & r tabel & Keterangan \\
\hline 1 & 0,520 & 0,3783 & Valid \\
2 & 0,454 & 0,3783 & Valid \\
3 & 0,743 & 0,3783 & Valid \\
4 & 0,479 & 0,3783 & Valid \\
5 & 0,824 & 0,3783 & Valid \\
6 & 0,684 & 0,3783 & Valid \\
7 & 0,615 & 0,3783 & Valid \\
8 & 0,754 & 0,3783 & Valid \\
9 & 0,413 & 0,3783 & Valid \\
10 & 0,704 & 0,3783 & Valid \\
11 & 0,719 & 0,3783 & Valid \\
12 & 0,620 & 0,3783 & Valid \\
13 & 0,668 & 0,3783 & Valid \\
14 & 0,547 & 0,3783 & Valid \\
15 & 0,622 & 0,3783 & Valid \\
16 & 0,568 & 0,3783 & Valid \\
17 & 0,257 & 0,3783 & Tidak \\
& & & Valid \\
18 & 0,770 & 0,3783 & Valid \\
19 & 0,691 & 0,3783 & Valid \\
20 & 0,708 & 0,3783 & Valid \\
21 & 0,807 & 0,3783 & Valid \\
22 & 0,867 & 0,3783 & Valid \\
23 & 0,888 & 0,3783 & Valid \\
24 & 0,888 & 0,3783 & Valid \\
25 & 0,868 & 0,3783 & Valid \\
\hline & & & \\
& & & \\
\hline
\end{tabular}

\section{Uji Reliabilitas Instrumen}

Berdasarkan hasil pre-test yang dilakukan, maka hasil uji reliabilitas dapat dilihat pada tabel berikut:

Tabel 3. Hasil Uji Reliabilitas

\begin{tabular}{lllll}
\hline No & Variabel & $\begin{array}{l}\text { Nilai } \\
\text { Cronbac } \\
\text { h's } \\
\text { Alpha }\end{array}$ & $\begin{array}{l}\text { Cronbac } \\
\text { h’s } \\
\text { Alpha }\end{array}$ & Ket \\
\hline 1 & $\begin{array}{l}\text { Kredibilitas } \\
\text { Brand } \\
\text { Ambassador }\end{array}$ & 0.740 & 0.70 & $\mathrm{R}$ \\
2 & $\begin{array}{l}\text { Proses } \\
\text { Keputusan } \\
\text { Pembelian }\end{array}$ & 0.757 & 0.70 & $\mathrm{R}$ \\
\hline
\end{tabular}

\section{Karakteristik Responden}

Berdasarkan hasil penelitian yang dilakukan, maka rekapitulasi karakteristik responden dapat dipaparkan seperti berikut:
Karakteristik Responden Berdasarkan Umur

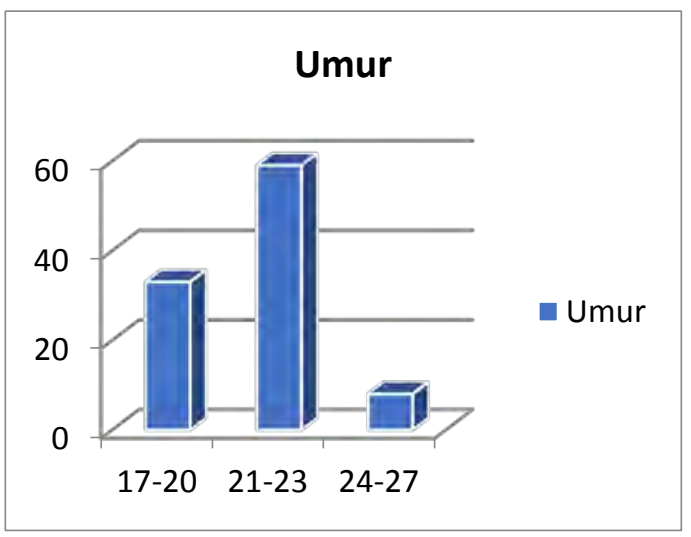

Karakteristik Responden Berdasarkan Jurusan

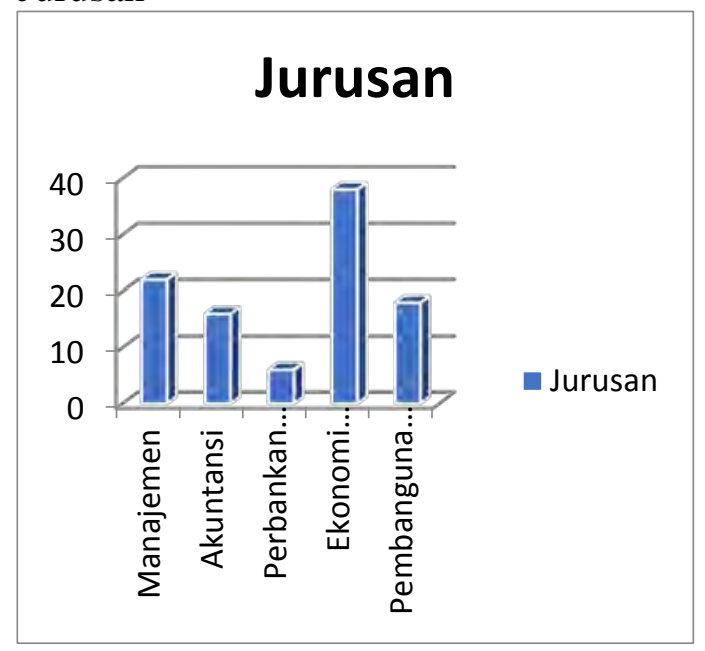

Karakteristik Responden Berdasarkan Semester

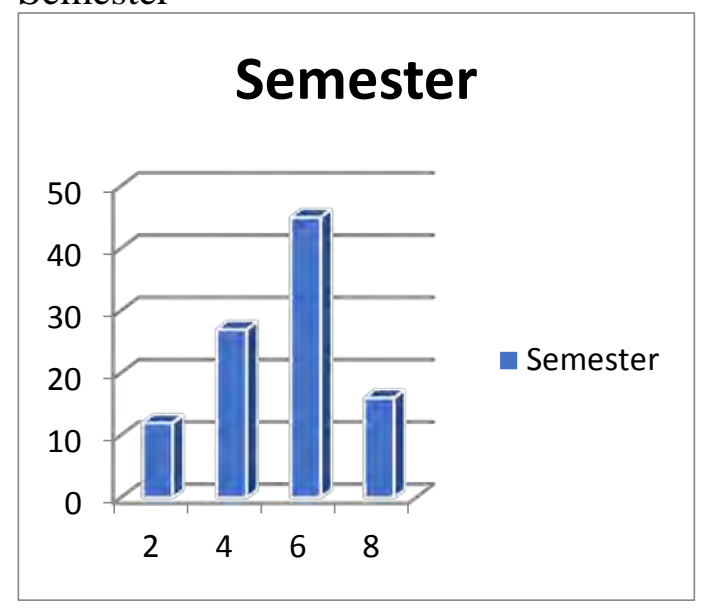

\section{Uji Asumsi Klasik}

Sebelum melakukan uji hipotesis terlebih dahulu dilakukan uji asumsi klasik yaitu uji normalitas dan uji lineritas. 
Tabel 4. Hasil Uji Normalitas

One-Sample Kolmogorov-Smirnov Test

\begin{tabular}{lll} 
& & \multicolumn{1}{c}{$\begin{array}{l}\text { Unstandardiz } \\
\text { ed Residual }\end{array}$} \\
\hline $\mathrm{N}$ & 100 \\
\hline $\begin{array}{l}\text { Normal } \\
\text { Parameters }\end{array}$ & Mean & .0000000 \\
\cline { 2 - 3 } $\begin{array}{l}\text { Most ExtremeAbsolute } \\
\text { Differences }\end{array}$ & Sositive & .072 \\
\cline { 2 - 3 } & Negative & -.042 \\
\hline Test Statistic & & .072 \\
\hline Asymp. Sig. (2-tailed) & $.200^{\mathrm{c}, \mathrm{d}}$ \\
\hline
\end{tabular}

Dari tabel 4 diatas dapat diketahui bahwa nilai Asymp signifikansi dari Unstandardized Residual sebesar 0,200 > 0,05, maka persamaan model regresi linier berganda memenuhi asumsi normalitas, sehingga dapat digunakan dalam penelitian.

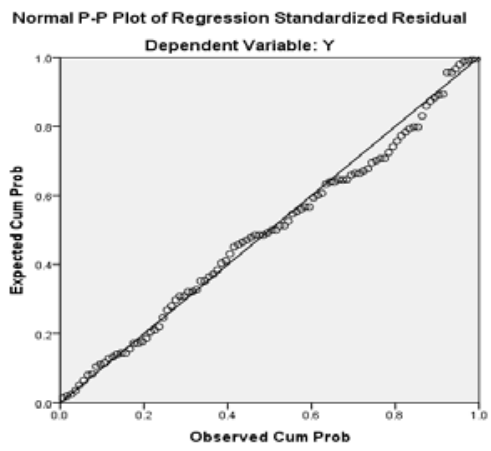

Grafik P-P Plot, dapat dilihat bahwa data menyebar di sekitar garis diagonal dan mengikuti arah garis diagonalnya. Dengan demikian, model regresi pada penelitian ini memenuhi asumsi normalitas.

Tabel 5. Hasil Uji Linieritas

\section{ANOVA Table}

\begin{tabular}{|c|c|c|c|c|c|c|c|}
\hline & & & $\begin{array}{l}\text { Sum o } \\
\text { Square } \\
\mathrm{s}\end{array}$ & Df & $\begin{array}{l}\text { Mean } \\
\text { Squar } \\
\text { e }\end{array}$ & $F$ & Sig. \\
\hline \multirow[t]{5}{*}{$\begin{array}{l}\bar{Y} \\
X\end{array}$} & $\begin{array}{l}{ }^{*} \text { Betw } \\
\text { een }\end{array}$ & $\begin{array}{l}\text { (Combi } \\
\text { ned) }\end{array}$ & $\begin{array}{l}1374.7 \\
78\end{array}$ & 21 & $\begin{array}{l}65.46 \\
6\end{array}$ & $\begin{array}{l}2.89 \\
3\end{array}$ & .000 \\
\hline & $\begin{array}{l}\text { Grou } \\
\text { ps }\end{array}$ & $\begin{array}{l}\text { Linearit } \\
y\end{array}$ & $\begin{array}{l}813.55 \\
4\end{array}$ & 1 & $\begin{array}{l}813.5 \\
54\end{array}$ & $\begin{array}{l}35.9 \\
48\end{array}$ & .000 \\
\hline & . & $\begin{array}{l}\text { Deviati } \\
\text { on from } \\
\text { Linearit } \\
\text { y }\end{array}$ & $\begin{array}{l}561.22 \\
4\end{array}$ & 20 & $\begin{array}{l}28.06 \\
1\end{array}$ & $\begin{array}{l}1.24 \\
0\end{array}$ & .246 \\
\hline & $\begin{array}{l}\text { Withi } \\
\text { Grou }\end{array}$ & & $\begin{array}{l}1765.2 \\
62\end{array}$ & 78 & $\begin{array}{l}22.63 \\
2\end{array}$ & & \\
\hline & Total & & $\begin{array}{l}3140.0 \\
40\end{array}$ & 99 & & & \\
\hline
\end{tabular}

Berdasarkan tabel 5 di atas dapat dilihat bahwa diperoleh probabilitas 0,246 > 0,05, maka dapat disimpulkan bahwa antara kredibilitas brand ambassador dengan proses keputusan pembelian mempunyai hubungan yang linear.

\section{Uji Hipotesis}

Uji hipotesis asosiatif/hubungan yang datanya berbentuk interval menggunakan teknik analis regresi linear sederhana, analisis korelasi sederhana, uji determinasi dan uji parsial (uji T). Hasil uji hipotesis sebagai berikut:

Tabel 6. Hasil Uji Regresi Linier Sederhana

Coefficientsa

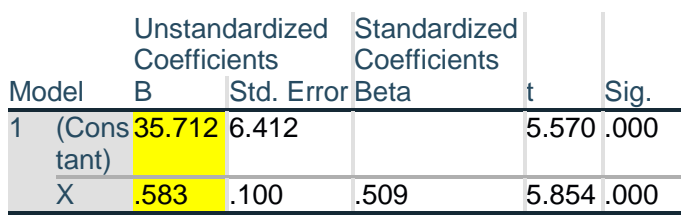

Adapun persamaan regresinya adalah sebagai berikut:

$$
\gamma=35,712+0,583 X
$$

Nilai 35,712 merupakan konstanta, artinya jika kredibilitas brand ambassador (X) nilainya adalah 0 , maka keputusan pembelian (Y) nilainya adalah sebesar 35,712. Sedangkan nilai koefisien arah regresi adalah positif yaitu sebesar 0,583, artinya jika ada penambahan satu nilai atau angka pada kredibilitas brand ambassador (X) maka akan ada kenaikan pada variabel keputusan pembelian (Y) sebesar 0,583.

Tabel 7. Hasil Uji Korelasi Sederhana

Correlations

\begin{tabular}{lll} 
& \multicolumn{1}{c}{$\mathrm{X}$} & $\mathrm{Y}$ \\
\hline $\mathrm{X}$ & $\begin{array}{l}\text { Pearson } 1 \\
\text { Correlation }\end{array}$ & $.509^{* *}$ \\
$\begin{array}{l}\text { Sig. } \quad(2- \\
\text { tailed })\end{array}$ & .000 \\
\hline $\mathrm{N}$ & 100 & 100 \\
\hline $\mathrm{Y}$ & $\begin{array}{l}\text { Pearson } .509^{* *} \\
\text { Correlation }\end{array}$ & 1 \\
\hline $\begin{array}{l}\text { Sig. } \quad(2-.000 \\
\text { tailed })\end{array}$ & $\mathrm{N}$ & 100 \\
\hline
\end{tabular}

Koefisien korelasi (R) antara variabel kredibilitas brand ambassador (X) dan keputusan pembelian (Y) sebesar 0,509. Berdasarkan pedoman interpretasi korelasi 
yang telah dikemukakan oleh Sugiyono, dapat disimpulkan bahwa terjadi hubungan yang cukup antara variabel kredibilitas brand ambassasdor (X) dan keputusan pembelian (Y).

Tabel 8. Hasil Analisis Koefisien Determinasi $\left(\mathrm{R}^{2}\right)$

Model Summary

Adjusted Std. Error of Model R R Square R Square the Estimate \begin{tabular}{lllll}
\hline 1 & $.509^{\mathrm{a}}$ & .259 & .252 & 4.872
\end{tabular}

Berdasarkan hasil perhitungan regresi menunjukan bahwa nilai $\mathrm{R}$ Square adalah sebesar 0,259. Hal tersebut menjelaskan bahwa sebesar $25,9 \%$ proses pengambilan keputusan pembelian konsumen dipengaruhi oleh kredibilitas brand ambassador, sedangkan sisanya yaitu $74,1 \%$ proses pengambilan keputusan pembelian konsumen dipengaruhi oleh variabel-variabel lainnya yang tidak diteliti dalam penelitian ini.

Tabel 9. Hasil Analisis Statistik Parsial (Uji T) Coefficients $^{\mathrm{a}}$

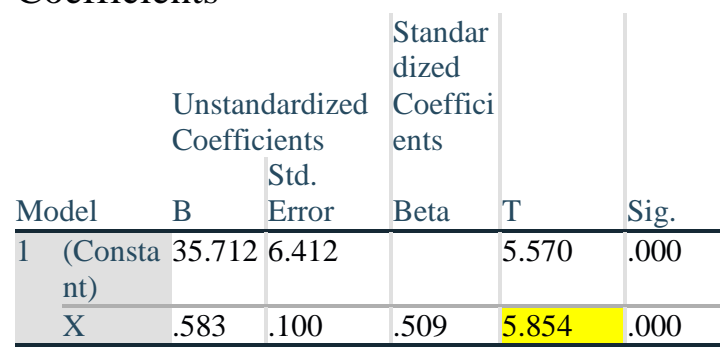

Diperoleh nilai t hitung sebesar 5,854. Nilai tersebut lebih besar dibandingkan dengan $\mathrm{t}$ tabel yaitu 1,2902. Dengan demikian, dapat disimpulkan bahwa variabel kredibilitas brand ambassador (X) memiliki pengaruh yang positif dan signifikan terhadap variabel proses keputusan pembelian dan Ha diterima.

\section{KESIMPULAN DAN SARAN}

Berdasarkan hasil penelitian dan pembahasan pada bab-bab sebelumnya, maka terbukti bahwa kredibilitas brand ambassador yakni Dewi Sandra memiliki pengaruh terhadap keputusan pembelian produk Wardah yang diuji kepada para mahasiswi Fakultas Ekonomi dan Bisnis UIN Syarif Hidayatullah Jakarta. Hasil penelitian tersebut dibuktikan melalui beberapa uji dan diantaranya menggunakan uji analisis regresi linear sederhana, hasil yang diperoleh dari nilai koefisien determinasi atau Adjust R Square sebesar 0,259. Hal ini berarti sebesar 25,9\% proses pengambilan keputusan pembelian konsumen dipengaruhi oleh kredibilitas brand ambassador, sedangkan sisanya yaitu $74,1 \%$ proses pengambilan keputusan pembelian konsumen dipengaruhi oleh variabel-variabel lainnya yang tidak diteliti dalam penelitian ini.

\section{DAFTAR PUSTAKA}

Buku

Belch, George E., Belch, Michael A (2009). Advertising and Promotion:

An Integrated Marketing

Communication Perpective. $\quad 8^{\text {th }}$

Edition. New York. McGraw Hill

Kotler, Philip \& Amstrong Gary. (2002).

Dasar-dasar Pemasaran. Jilid

1, Alih bahasa Alexander Sindoro

\& Benyamin Molan:

Prenhalindo.

Kotler, Philip \& Gary Amstrong. 2004. Dasar-dasar Pemasaran, Edisi

kesembilan, Jilid 1, dialihbahasakan oleh Alexander Sindoro, Jakarta: Indeks

Kotler, Philip dan Kevin Lane Keller. 2009. Manajemen Pemasaran Jilid

1. Edisi ketigabelas. Jakarta: Erlangga.

Mulyana, Deddy. 2000. Ilmu Komunikasi Suatu Pengantar. Bandung. PT Remaja Rosdakarya

Rakhmat, Jalaludin. 2003. Psikologi Komunikasi. Bandung. PT Remaja Rosdakarya

Royan, Frans M. 2004. Cluster Strategy. Jakarta: Gramedia Pustaka

Schiffman \& Kanuk. 2004. Perilaku Konsumen (Edisi 7). Jakarta.

Prentice Hall 
Shimp, Terence A. 2003. Periklanan dan Promosi. Erlangga, Jakarta

Sudaryono. 2014. Perilaku Konsumen dalam Perspektif Pemasaran. Cetakan pertama. Jakarta Pusat: Lentera Ilmu Cendekia.

Sugiyono. 2011. Metode Penelitian Bisnis. Bandung: Alfabeta. . 2012. Metode Penelitian Bisnis. Bandung: Alfabeta

Tjiptono, Fandy. 2007. Pemasaran Jasa. Yogyakarta: Andi.

2014. Pemasaran Jasa. Yogyakarta: Andi.

Umar, Husein. 2013. Metode Penelitian untuk Skripsi dan Tesis Bisnis. Jakarta: Rajawali Pers.

2013. Metode Penelitian kuantitatif, kualitatif dan R\&D. Bandung: Alfabeta.

Sugiyono. 2012 Metode Penelitian Bisnis. Bandung: Alfabeta.

Sunyoto, Danang. 2012. Dasar-Dasar Manajemen Pemasaran. Yogyakarta: CAPS.

Jurnal Online

Fakrulloh, Fadilah. 2013. Analisis Pengaruh Kredibilitas Celebrity Brand ambassador dan Daya Tarik Iklan terhadap Brand Awareness Motor Matic Honda Vario di Kecamatan Bangsal Mojokerto (Studi pada UD.

Tirto Agung Mojokerto). UPN Veteran Jawa Timur.

Nuraini, Puti. 2015. Pengaruh Kredibilitas Brand ambassador Band NOAH dalam Iklan Vaseline Men terhadap Keputusan Membeli Produk. Universitas Sultan Ageng Tirtayasa.

Susila, Arwan Mega. 2008. Pengaruh Kredibilitas Celebrity Brand ambassador terhadap Sikap Konsumen pada Merek Esia (Studi pada Artis Ringgo Agus Rahman). Universitas Indonesia.
Website

http://www.pticosmetics.com/about/hist ory diakses 14/4/17 01:42

http://www.wardahbeauty.com/en/about /story 14/4/17 01:46

http://www.pengertianmenurutparaahli. net/pengertian-kredibilitas-dancontohnya/ diakses pada 16/4/17 23:45

http://www.seputarpengetahuan.com/20 15/03/100-macam-pengertiankomunikasi-menurut-paraahli.html diakses pada diakses pada 2/5/17 23:50

http://www.pendidikanekonomi.com/20 13/02/selebriti-sebagaiendorser-produk-dalam.html 2/5/17 pukul 10.31

http://www.uinjkt.ac.id/rektor-jumlahmahasiswa-uin-jakarta-terusbertambah/ 03/05/17 pukul 21.23 
